\title{
Article
}

\section{RP11-362K2.2:RP11-767I20.1 Genetic Variation Is Associated with Post-Reperfusion Therapy Parenchymal Hematoma. A GWAS Meta-Analysis}

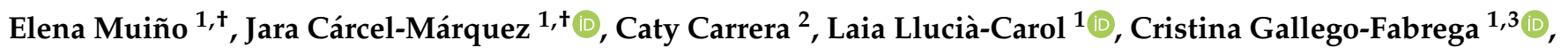 \\ Natalia Cullell ${ }^{1,4}$, Miquel Lledós ${ }^{1}{ }^{(\mathbb{D}}$, José Castillo ${ }^{5}$, Tomás Sobrino ${ }^{5}$ (), Francisco Campos ${ }^{5}{ }^{(}$, \\ Emilio Rodríguez-Castro ${ }^{6}$, Mònica Millán ${ }^{7}$, Lucía Muñoz-Narbona ${ }^{7}{ }^{\mathbb{D}}$, Alejandro Bustamante ${ }^{7}$, \\ Elena López-Cancio ${ }^{8}$, Marc Ribó ${ }^{9}$, José Álvarez-Sabín ${ }^{10}$, Jordi Jiménez-Conde ${ }^{11}$, Jaume Roquer ${ }^{11}$ (D), \\ Eva Giralt-Steinhauer ${ }^{11}$, Carolina Soriano-Tárraga ${ }^{11}$ (D) Cristófol Vives-Bauza ${ }^{12}$, Rosa Díaz Navarro ${ }^{13}$, \\ Silvia Tur ${ }^{13}$, Victor Obach ${ }^{14}$, Juan F. Arenillas ${ }^{15} \mathbb{D}$, Tomás Segura ${ }^{16} \mathbb{D}$, Gemma Serrano-Heras ${ }^{17} \mathbb{D}$, \\ Joan Martí-Fàbregas ${ }^{3}$ (D), Raquel Delgado-Mederos ${ }^{3}$, Pol Camps-Renom ${ }^{3}{ }^{D}$, Luis Prats-Sánchez ${ }^{3}$, \\ Daniel Guisado ${ }^{3}$, Marina Guasch ${ }^{3}$, Rebeca Marin ${ }^{3}$ (D), Alejandro Martínez-Domeño ${ }^{3}$, \\ Maria del Mar Freijo-Guerrero ${ }^{18}$, Francisco Moniche ${ }^{19}$ (D), Juan Antonio Cabezas ${ }^{19}$, Mar Castellanos ${ }^{20}$, \\ Jerzy Krupinsky 21,22, Daniel Strbian ${ }^{23}$, Turgut Tatlisumak ${ }^{24,25}$, Vincent Thijs 26,27, Robin Lemmens ${ }^{28}$, \\ Agnieszka Slowik ${ }^{29}$, Joanna Pera ${ }^{29}$ (D) Laura Heitsch ${ }^{30,31}$, Laura Ibañez ${ }^{32}$, Carlos Cruchaga ${ }^{32}$ (D), Rajat Dhar ${ }^{31}$, \\ Jin-Moo Lee ${ }^{31}$, Joan Montaner ${ }^{19}$, Israel Fernández-Cadenas ${ }^{1, *}$, \\ on behalf of International Stroke Genetic Consortium and the Spanish Stroke Genetic Consortium
}

Citation: Muiño, E.; Cárcel-Márquez, J.; Carrera, C.; Llucià-Carol, L.; Gallego-Fabrega, C.; Cullell, N.; Lledós, M.; Castillo, J.; Sobrino, T.; Campos, F.; et al.

RP11-362K2.2:RP11-767I20.1 Genetic Variation Is Associated with Post-Reperfusion Therapy Parenchymal Hematoma. A GWAS Meta-Analysis. J. Clin. Med. 2021, 10, 3137. https://doi.org/10.3390/ jcm10143137

Academic Editor: Hyo Suk Nam

Received: 7 June 2021

Accepted: 14 July 2021

Published: 16 July 2021

Publisher's Note: MDPI stays neutral with regard to jurisdictional claims in published maps and institutional affiliations.

Copyright: (c) 2021 by the authors. Licensee MDPI, Basel, Switzerland. This article is an open access article distributed under the terms and conditions of the Creative Commons Attribution (CC BY) license (https:// creativecommons.org/licenses/by/ $4.0 /$ )
1 Stroke Pharmacogenomics and Genetics Group, Institut de Recerca de l'Hospital de la Santa Creu i Sant Pau, 08041 Barcelona, Spain; elena.muinho@gmail.com (E.M.); jara.carcel@gmail.com (J.C.-M.); laialluciacarol@gmail.com (L.L.-C.); cristina.gallego.fabrega@gmail.com (C.G.-F.); natalia.cullell@gmail.com (N.C.); miquel.lledos@gmail.com (M.L.)

2 Neurovascular Research Laboratory, Vall d'Hebron Institut de Recerca, Universitat Autònoma de Barcelona, 08025 Barcelona, Spain; catycarrerav@gmail.com

3 Department of Neurology, Hospital de la Santa Creu i Sant Pau, IIB-Sant Pau, 08025 Barcelona, Spain; jmarti@santpau.cat (J.M.-F.); rdelgado@santpau.cat (R.D.-M.); pcamps@santpau.cat (P.C.-R.); LPratsS@santpau.cat (L.P.-S.); DGuisado@santpau.cat (D.G.); MGuasch@santpau.cat (M.G.); rmarin@santpau.cat (R.M.); amartinezd@santpau.cat (A.M.-D.)

4 Stroke Pharmacogenomics and Genetics, Fundació MútuaTerrassa per la Docència i la Recerca, 08221 Terrassa, Spain

5 Clinical Neurosciences Research Laboratories, Health Research Institute of Santiago de Compostela (IDIS), 15706 Santiago de Compostela, Spain; jose.castillo.sanchez@sergas.es (J.C.); Tomas.Sobrino.Moreiras@sergas.es (T.S.); francisco.campos.perez@sergas.es (F.C.)

6 Department of Neurology, Hospital Clínico Universitario de Santiago, 15706 Santiago de Compostela, Spain; emiliorcastro@gmail.com

7 Department of Neuroscience, Hospital Germans Trias i Pujol, 08025 Badalona, Spain; mmillan.germanstrias@gencat.cat (M.M.); luciamunozn@gmail.com (L.M.-N.); alebustamanterangel@gmail.com (A.B.)

8 Stroke Unit, Hospital Universitario Central de Asturias, 33011 Oviedo, Spain; elenacancio@gmail.com

9 Stroke Unit, Hospital Universitario Valle de Hebrón, 08025 Barcelona, Spain; marcriboj@hotmail.com

10 Department of Neurology, Hospital Universitario Valle de Hebrón, Universidad Autónoma de Barcelona, 08025 Barcelona, Spain; josalvar@vhebron.net

11 Department of Neurology, Neurovascular Research Group, Instituto de Investigaciones Médicas Hospital del Mar-Hospital del Mar, 08025 Barcelona, Spain; jjimenez@imim.es (J.J.-C.); jroquer@hospitaldelmar.cat (J.R.); egiralt@imim.es (E.G.-S.); csoriano@imim.es (C.S.-T.)

12 Neurobiology Laboratory, Instituto de Investigación Sanitaria de Palma, 07120 Mallorca, Spain; cristofol.vives@ssib.es

13 Department of Neurology, Hospital Universitari Son Espases, 07120 Mallorca, Spain; rosam.diaz@ssib.es (R.D.N.); silvia.tur@ssib.es (S.T.)

14 Department of Neurology, Hospital Clínic i Provincial de Barcelona, 08025 Barcelona, Spain; VOBACH@clinic.cat

15 Department of Neurology, Hospital Clínico Universitario, University of Valladolid, 47003 Valladolid, Spain; juanfarenillas@gmail.com

16 Department of Neurology, Complejo Hospitalario Universitario de Albacete, 02006 Albacete, Spain; tseguram@gmail.com 
17 Experimental Research Unit, Complejo Hospitalario Universitario de Albacete, 02006 Albacete, Spain; gemmas@sescam.jccm.es

18 Neurovascular Unit, Biocruces Bizkaia Health Research Institute, 48903 Bilbao, Spain; marimar.freijoguerrero@osakidetza.eus

19 Department of Neurology, Virgen del Rocío, Instituto de Biomedicina de Sevilla, 41013 Seville, Spain; pmoniche@gmail.com (F.M.); juancaro.jacr@gmail.com (J.A.C.); joan.montaner@vhir.org (J.M.)

20 Department of Neurology, Complejo Hospitalario Universitario A Coruña, 15006 A Coruña, Spain; Maria.del.Mar.Castellanos.Rodrigo@sergas.es

21 School of Healthcare Science, Manchester Metropolitan University, Manchester M15 6BH, UK; jkrupinski@mutuaterrassa.es

22 Neurology Unit, Hospital Universitari Mútua Terrassa, 08221 Terrassa, Spain

23 Department of Neurology, Helsinki University Hospital, FI-00029 Helsinki, Finland; daniel.strbian@hus.fi

24 Department of Clinical Neuroscience, Institute of Neurosciences and Physiology, Sahlgrenska Academy at University of Gothenburg, 41345 Gothenburg, Sweden; turgut.tatlisumak@neuro.gu.se

25 Department of Neurology, Sahlgrenska University Hospital, 41345 Gothenburg, Sweden

26 Stroke Division, Florey Institute of Neuroscience and Mental Health, University of Melbourne, Heidelberg VIC 3072, Australia; vincent.thijs@austin.org.au

27 Department of Neurology, Austin Health, Heidelberg VIC 3072, Australia

28 Department of Neurology, University Hospitals Leuven, Campus Gasthuisberg, 3000 Leuven, Belgium; robin.lemmens@uzleuven.be

29 Department of Neurology, Jagiellonian University Medical College, 31-007 Kraków, Poland; slowik@neuro.cm-uj.krakow.pl (A.S.); pera@su.krakow.pl (J.P.)

30 Division of Emergency Medicine, Washington University School of Medicine, St. Louis, MO 63110-1010, USA; lheitsch@wustl.edu

31 Department of Neurology, Washington University School of Medicine, St. Louis, MO 63110-1010, USA; dharr@wustl.edu (R.D.); leejm@wustl.edu (J.-M.L.)

32 Department of Psychiatry, Washington University School of Medicine, St. Louis, MO 63110-1010, USA; ibanezl@wustl.edu (L.I.); cruchagac@wustl.edu (C.C.)

* Correspondence: israelcadenas@yahoo.es

+ E.M. and J.C.-M. contributed equally to this work.

Abstract: Stroke is one of the most common causes of death and disability. Reperfusion therapies are the only treatment available during the acute phase of stroke. Due to recent clinical trials, these therapies may increase their frequency of use by extending the time-window administration, which may lead to an increase in complications such as hemorrhagic transformation, with parenchymal hematoma $(\mathrm{PH})$ being the more severe subtype, associated with higher mortality and disability rates. Our aim was to find genetic risk factors associated with $\mathrm{PH}$, as that could provide molecular targets/pathways for their prevention/treatment and study its genetic correlations to find traits sharing genetic background. We performed a GWAS and meta-analysis, following standard quality controls and association analysis (fastGWAS), adjusting age, NIHSS, and principal components. FUMA was used to annotate, prioritize, visualize, and interpret the meta-analysis results. The total number of patients in the meta-analysis was 2034 (216 cases and 1818 controls). We found rs79770152 having a genome-wide significant association (beta $0.09, p$-value $3.90 \times 10^{-8}$ ) located in the RP11-362K2.2:RP11-767I20.1 gene and a suggestive variant (rs13297983: beta 0.07, $p$-value $6.10 \times 10^{-8}$ ) located in PCSK5 associated with PH occurrence. The genetic correlation showed a shared genetic background of $\mathrm{PH}$ with Alzheimer's disease and white matter hyperintensities. In addition, genes containing the ten most significant associations have been related to aggregated amyloid- $\beta$, tau protein, white matter microstructure, inflammation, and matrix metalloproteinases.

Keywords: hemorrhagic transformation; parenchymal hematoma; GWAS; single nucleotide variants

\section{Introduction}

Stroke is the second most common cause of death worldwide, and the third most common cause of disability [1]. For ischemic strokes, the only treatments available during the acute phase are the reperfusion therapies such as thrombolysis and mechanical thrombectomy. 
Ischemic strokes may present hemorrhagic transformation (HT). This may be early, associated with reperfusion of the occluded vessel; or late, which is thought to be related to increased permeability and blood flow [2].

HT is a well-recognized complication following reperfusion therapies. HT could be classified, according to the European Cooperative Acute Stroke Study (ECASS) criteria, into petechial infarction without space-occupying effect (HI) and hematoma/coagulum with mass effect $(\mathrm{PH})[2]$.

HT may result in neurological deterioration [3], and the presence of a PH independently predicts early and late mortality, with a hazard ratio of late mortality of 7.9 , with a 95\% confidence interval (CI) of 2.9-21.4 [4]. Nevertheless, petechial changes may indicate that reperfusion occurred when the ischemic tissue was still at least partially viable.

Patients exhibiting an early $\mathrm{HI}$ did not have a higher risk of neurological deterioration compared with patients without hemorrhagic transformation. Among patients treated with rtPA, HI was even loosely associated with early improvement. Overall, three-month mortality and disability were also not influenced by HI [2].

The percentage of HT in studies of stroke patients varies from $6.4 \%$ to $43 \%$ [3], and the use of reperfusion therapies has favored the increase in this incidence. Moreover, clinical trials such as WAKE-UP [5], DAWN [6], or DEFUSE 3 [7] will allow a major use of these therapies, extending the time-window administration, which may lead to an increase in HT. It is therefore of utmost importance to identify those patients at higher risk of suffering a PH, as this is the subtype of HT that causes the highest morbidity and mortality [2,4].

There is a genetic predisposition for HTs following intravenous thrombolysis (IVT). This genetic contribution has been explored through candidate genes [8,9] or more recently through a Genome Wide Association Study (GWAS), carried out by our own group [10]. In this last study, we found that single nucleotide variants (SNVs) in the ZBTB46 gene were associated with PH in patients who underwent IVT [10]. For this purpose, we studied the extreme phenotype, patients with $\mathrm{PH}$ vs. patients without $\mathrm{HT}$, excluding patients with petechial infarction (HI) subtype.

We decided to carry out a new analysis by including in the control group those patients who had a HI, to ensure that the findings achieved are exclusively attributed to the PH subtype due to reperfusion therapies, including patients that underwent mechanical thrombectomy or intra-arterial fibrinolysis, increasing our sample size, and with it, our statistical power.

Currently, articles using GWAS to understand different diseases are complemented by the study of genetic correlations with other traits to find common genetic architecture [11]. Knowing which traits share a genetic correlation allows a better understanding of diseases and the realization of further studies to find variants associated with them by increasing its statistical power, such as multitrait analysis of GWAS (MTAG). As example, the article performing a MTAG of small vessel occlusion strokes and intracerebral hemorrhage, due to these traits sharing a genetic background, allows us to find new loci associated with these diseases [12].

In the article we mentioned above, published by our group, we found that $\mathrm{PH}$ shared a genetic background with deep intracerebral hemorrhage (ICH), lobar ICH, and white matter hyperintensities (WMH) [10]. After Bonferroni correction, only lobar ICH remained significantly correlated.

Therefore, the aim of our study was to find genetic risk factors associated exclusively with $\mathrm{PH}$, including patients with different reperfusion treatments. $\mathrm{PH}$ occurrence is still an important problem in the reperfusion strategy for stroke patients. Hence the importance of finding molecules that could be used as biomarkers to guide the therapeutic decision or potential therapeutic targets to prevent the appearance of this life-threatening complication. We also wanted to assess whether the same genetic correlations found in our previous paper were still found and whether we could find any new ones.

In this work we found a genome-wide significant locus associated with $\mathrm{PH}$, regardless of the reperfusion treatment performed. Moreover, we found that there is a genetic 
correlation of PH with Alzheimer's disease and white matter hyperintensities (WMH). In fact, the study of nominally significant genomic loci in the meta-analysis has shown that pathways related to aggregated amyloid- $\beta$, tau protein, and inflammatory pathways could be related to $\mathrm{PH}$ occurrence.

\section{Materials and Methods}

This is an observational case-control study, conducted in a discovery and replication cohort, with subsequent meta-analysis of both results, in order to find SNVs associated with PH.

\subsection{Subjects}

\subsubsection{Discovery Cohort}

The participants included in the discovery cohort were part of the Genetic Study in Ischemic Stroke Patients treated with recombinant tissue plasminogen activator (r-tPA) (GenoTPA) [9], Genetic contribution to Functional Outcome and Disability after Stroke (GODS) [13], the Genotyping Recurrence Risk of Stroke (GRECOS) [14], and Genetics of Early Neurological Instability After Ischemic Stroke (GENISIS) [15] studies. These studies have, in common, the recruitment of patients with ischemic stroke between 2002 and 2020.

From these four studies, $(n=4667), 161$ cases (patients with $\mathrm{PH}$ after reperfusion therapy) and 1236 controls (patients without $\mathrm{PH}$ after reperfusion therapy) fulfilled the inclusion and exclusion criteria, incorporated in a total of 8 batches (Table 1). All of the subjects of the discovery cohort had a Spanish origin.

Table 1. Discovery cohort.

\begin{tabular}{ccccccc}
\hline Study & Total & Cases & Controls & Arrays & Batches & Country \\
\hline GenoTPA [9] & 240 & 34 & 180 & HumanOmni1-Quad BeadChip (Illumina) & 1 & Spain \\
GODS [13] & 993 & 28 & 342 & HumanCoreExome (Illumina) & 1 & Spain \\
GRECOS [14] & 214 & 3 & 0 & HumanCoreExome (Illumina) & 1 & Spain \\
GENISIS [15] & 3220 & 96 & 714 & HumanCoreExome (Illumina) & 5 & Spain \\
Total & 4667 & 161 & 1236 & & 8 & Spain \\
\hline
\end{tabular}

GenoTPA: Genetic Study in Ischemic Stroke Patients treated with recombinant tissue plasminogen activator (r-tPA); GODS: Genetic contribution to Functional Outcome and Disability after Stroke; GRECOS: Genotyping Recurrence Risk of Stroke study; GENISIS: Genetics of Early Neurological Instability After Ischemic Stroke.

\subsubsection{Replication Cohort}

The participants included in the replication cohort were part of the Genetic Study in Ischemic Stroke Patients treated with tPA (GenoTPA) [9], BAse de Datos de ICtus del hospital del MAR (BASICMAR) (Stroke database of the Hospital del Mar) [16], Leuven Stroke Genetics Study (LSGS) [17], Helsinki 2000 Ischemic Stroke Genetics Study, and Genetics of Early Neurological Instability After Ischemic Stroke (GENISIS) [15] studies.

From these five studies, the imputed genotype was available from a total of 1064 patients, 112 cases and 913 controls, incorporated in a total of 7 batches (Table 2).

For a detailed description of the different studies included in the discovery and replication cohorts see Supplemental Methods.

\subsubsection{Variables}

Detailed clinical-epidemiological data was collected from each patient, including age, sex, vascular risk factors such as hypertension, diabetes mellitus (DM), dyslipidemia (DLP), smoking habits, history of atrial fibrillation (AF), physical examination including stroke severity assessed with the National Institutes of Health Stroke Scale (NIHSS) at initial evaluation and the modified Rankin Score (mRS) prior to stroke, systolic (SBP) and diastolic blood pressure (DBP), initial glycaemia, TOAST classification, or treatment decisions. In Supplemental Methods, there is detailed information about variable definition. 
CT scans were obtained prior to reperfusion procedure (baseline), and $24 \mathrm{~h}$ after, or whenever a neurological deterioration detected by the clinician was observed, to assess the presence of HT and its degree. All brain images were reviewed by a radiologist or neuro-radiologist.

Table 2. Replication cohort.

\begin{tabular}{ccccccc}
\hline Study & Total & Cases & Controls & Arrays & Batches & Country \\
\hline GenoTPA [9] & 157 & 36 & 121 & HumanOmni1-Quad BeadChip (Illumina) & 1 & Spain \\
BASICMAR & 91 & 8 & 83 & Human Omni Quad 5M (Illumina) & 1 & Spain \\
LSGS & 45 & 8 & 37 & Human Omni Quad 5M (Illumina) & 1 & Belgium \\
HELSINKI2000 & 164 & 12 & 152 & HumanCoreExome (Illumina) & 1 & Finland \\
& 70 & 2 & 68 & HumanCoreExome (Illumina) & 1 & Finland \\
GENISIS [15] & 53 & 4 & 49 & HumanCoreExome (Illumina) & 1 & Poland \\
& 484 & 42 & 403 & HumanCoreExome (Illumina) & 1 & Spain \\
Total & 1064 & 112 & 913 & & & Spain \\
\hline
\end{tabular}

GenoTPA: Genetic Study in Ischemic Stroke Patients treated with recombinant tissue plasminogen activator (r-tPA); BASICMAR: BAse de Datos de ICtus del hospital del MAR; LSGS: Leuven Stroke Genetics Study; HELSINKI2000: Helsinki 2000 Ischemic Stroke Genetics Study; and Genetics of Early Neurological Instability After Ischemic Stroke studies.

HT was classified, according to the ECASS criteria, into petechial infarction without space-occupying effect (HI) with two subtypes, HI1 (small petechiae) and HI2 (more confluent petechiae); and hematoma/coagulum with mass effect $(\mathrm{PH})$ divided into $\mathrm{PH} 1$ when affecting $\leq 30 \%$ of the infarct bed with mild mass effect and $\mathrm{PH} 2$, when affecting $>30 \%$ of the infarct bed with significant mass effect or remote hemorrhage [2].

As the aim of our study was to find SNV associated with the risk of PH (PH1 and PH2) after reperfusion treatment, patients without HT or with HI (HI1 and HI2) were chosen as controls, and patients with PH were chosen as cases. Remote hemorrhages were excluded from the study, as their etiology has not yet been clarified and the biological mechanisms underlying remote hemorrhages are probably different compared to the other HTs [18].

\subsubsection{Eligibility Criteria}

For the association study, patients $>18$ years of age with an ischemic stroke that underwent reperfusion therapy (ITV, including mechanical thrombectomy or intra-arterial fibrinolysis as second intention), who presented with $\mathrm{PH}$, were considered as cases. Controls were selected as patients $>18$ years with ischemic stroke that underwent reperfusion therapy, who did not present HT or who presented with HI.

Exclusion criteria: patients not receiving reperfusion therapy, who suffered a remote PH or unknown HT phenotype.

\subsubsection{Standard Protocol Approvals and Patient Consent}

This study was approved by the local ethics committee of each participant and an informed consent document was signed by every patient or their relatives.

\subsection{Genotyping}

DNA samples were genotyped on commercial arrays from Illumina (San Diego, CA, USA) (Tables 1 and 2).

\subsubsection{Quality Control}

For detailed quality controls performed see Supplemental Methods.

Briefly, SNV missing in a large proportion of the subjects, non-biallelic SNV, ambiguous, monomorphic or duplicated SNV, or SNV that violates the Hardy-Weinberg (dis)equilibrium (HWE) law were deleted.

Individuals with high rates of genotype missingness, sex discrepancy or unknown sex, family members or duplicated samples, non-European individuals, and patients with outlier heterozygosity rates $(n=814)$ were removed. 
After all these QCs, the total number of patients was 141 cases and 1003 controls in the discovery cohort. To ensure that there were no duplicate samples between the discovery and replication cohorts, patients with a pihat $>0.8$ were removed from replication cohort. The number of patients with information for the covariates introduced in the analysis were 1139, 140 cases and 999 controls.

Finally, 895 patients (76 cases and 819 controls) passed the QC and had information for the covariates in the analysis, constituting the replication cohort.

Studies genotyped on the same platforms were combined in the discovery cohort. For the replication cohorts data were already imputed [10].

\subsubsection{Genome Build}

All genomic coordinates are given in NCBI Build 37/UCSC hg19.

\subsection{Imputation}

Imputation was performed with the Michigan Imputation Server Pipeline using Minimac4, following their instructions (https: / / imputationserver.readthedocs.io/en/latest (accessed on 1 May 2021)). HRC r1.1 2016 (GRCh37/hg19) was the reference panel used, with European population and, for phasing, Eagle v2.4 was used.

After imputation, QC were performed. We removed SNV with $\mathrm{r}^{2}<0.6$ and $\mathrm{MAF}<0.1 \%$. After merging all cohorts, SNVs that were not present in at least $90 \%$ of the individuals were removed.

\subsection{Genome-Wide Association Analysis and Meta-Analysis}

We performed a linear regression-based association analysis using fastGWAS [19]. Those SNV with minor allele count $(\mathrm{MAC})<6$ were subsequently removed. For the discovery cohort, we adjusted for the first two principal components (PC) (Figure 1), age and the variables remaining significant in the multivariable logistic regression $(p$-value $<0.05)$ and that we had information on the replication cohort: NIHSS. For the replication cohort, the analysis was adjusted for the three first PC (Figure 1), and the same clinical variables as in the discovery analysis: age and NIHSS.

Due to the small sample size of the discovery cohort, in order to increase statistical power, we carried out a meta-analysis of the results of the discovery and replication cohort with the metal software (http:/ / csg.sph.umich.edu/abecasis/metal (accessed on 5 May 2021)), weighted by the number of individuals contributing to each result [20]. Genomic control correction was applied to both input files and then to the meta-analysis results.

A $p$-value $<5 \times 10^{-8}$ was considered genome-wide significant and a $p$-value $<1 \times 10^{-5}$ a nominal genome-wide association.

\subsection{Functional Annotation of Associated Variants}

FUMA (Functional Mapping and Annotation of Genome-Wide Association Studies) was used to annotate, prioritize, visualize, and interpret the meta-analysis results (https: / / fuma.ctglab.nl (accessed on 6 May 2021)) [21]. This platform also permits the realization of an ANNOVAR enrichment test; MAGMA gene analysis, gene-set analysis and geneproperty analysis; identification of expression quantitative trait loci (eQTL), chromatin interaction data, and mapping. It also provides information about the RegulomeBD score. This score, that provides information on the probability of affect binding and expression of target gene, goes from 1 (most likely) to 7 (least likely). As a reference panel, we used UKB release $2 \mathrm{~b} 10 \mathrm{k}$ European population.

To search for traits to which the genes closest to the most significant SNVs have been related, we used the GWAS Catalog (https:/ / www.ebi.ac.uk/gwas (accessed on 6 May 2021)).

For finding gene ontology (GO) terms of the genes of interest, we performed a search in Ensembl (https:/ / www.ensembl.org/index.html (accessed on 6 May 2021)). 


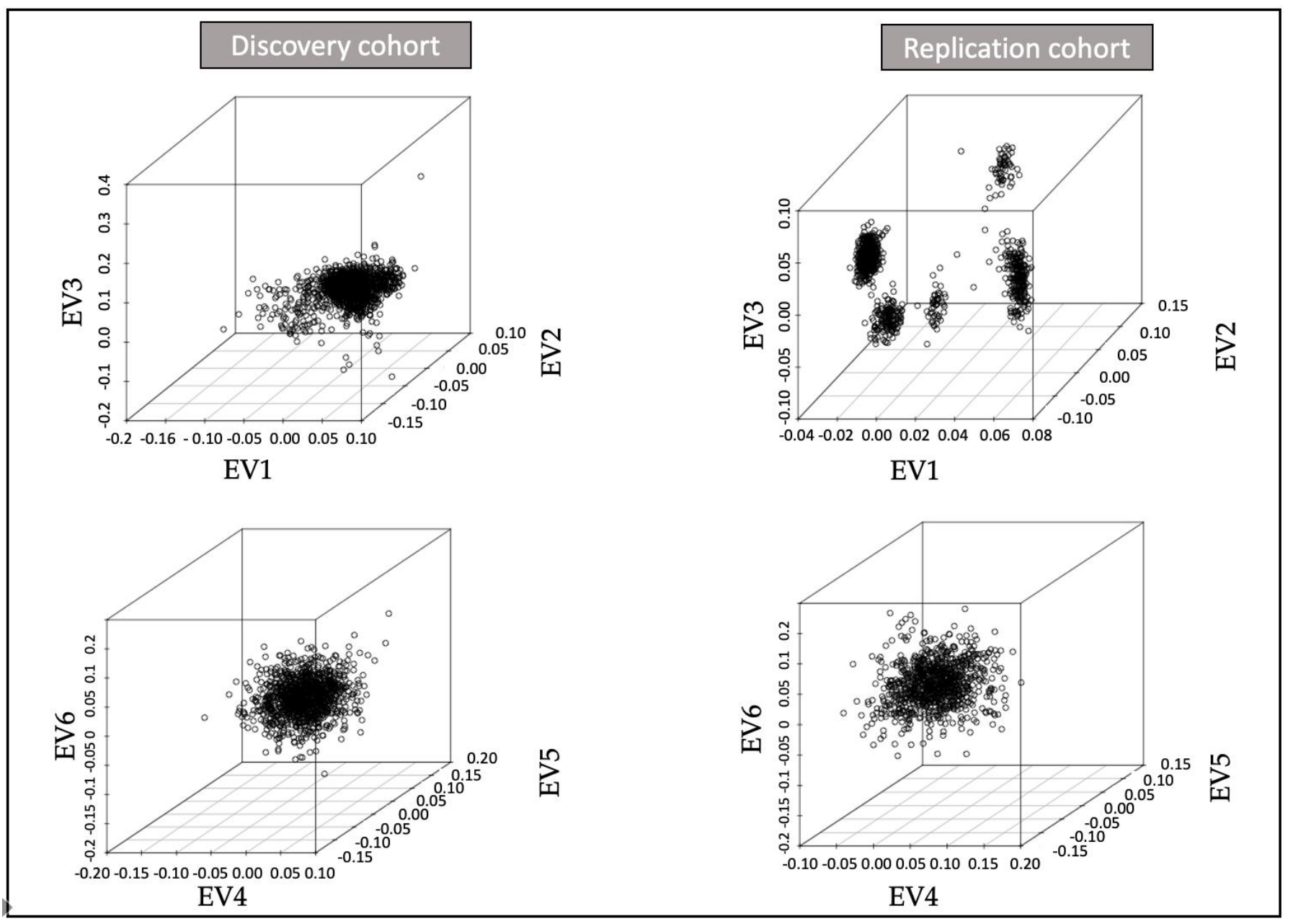

Figure 1. Principal component analysis (PCA) representation for discovery and replication cohorts. EV: eigenvector.

\subsection{Estimation of Genetic Correlations}

We used GNOVA (GeNetic cOVariance Analyzer) to estimate genetic covariance and correlation between traits. For this estimation, GNOVA only requires the genetic information available in the summary statistics of the traits of interest.

We tested genetic correlation for traits that have been related with HT: any ischemic strokes (AIS, $n=440,328$ ), large artery atherosclerosis strokes (LAS, $n=301,663$ ), cardieombolic strokes (CES, $n=362,661$ ), and small vessel occlusion strokes (SVO, $n=348,946$ ) using MEGASTROKE European data [22], deep intracerebral hemorrhage $(n=2075)$ [23], lobar intracerebral hemorrhage $(n=1148)$ [23], white matter hyperintensities $(\mathrm{WMH}$, $n=11,226)$ [24], Alzheimer's disease (AD, $n=63,926)$ [11], total cholesterol $(n=94,595)$ [25], LDL $(n=94,595)$ [25], HDL $(n=94,595)$ [25], triglycerides $(n=94,595)$ [25], sistolic blood pressure (SBP, $n=757,601$ ) [26], diastolic blood pressure (DBP, $n=757,601$ ) [26], and diabetes mellitus 2 (DM2) $(n=69,033)$ [27].

\subsection{Statistical Analyses}

$\mathrm{R}$ version 3.6.3 and Bioconductor packages were used to perform the statistical analysis. To study whether there were significant differences $(p$-value $<0.05)$ between cases and controls in the discovery and replication cohorts, for quantitative variables with a normal distribution, we used $t$-test and a Mann-Whitney $\mathrm{U}$ for non-normal quantitative or ordinal variables. The Chi-square test was used for categorical variables.

Multivariable logistic regression was conducted following a forward stepwise approach to select clinical variables as covariates for the association study. First, univariable 
logistic regression was performed to study the association between the available variables and the occurrence of $\mathrm{PH}$. Then, they were added to the multivariable logistic regression model according to their $p$-value, from the most significant to the least.

Variables with more than $10 \%$ missing values (less than 1030 observations) were not taken into account for the multivariate model (DLP, smoking habits, mRS, SBP, DBP, intraarterial fibrinolysis, and mechanical thrombectomy), as the results of subsequent statistical analyses might be biased [28] and the analysis underpowered.

\subsection{Data Availability}

The data that supports the findings of this study is available from the corresponding author upon reasonable request.

\section{Results}

\subsection{Descriptive Analysis of the Cohorts}

\subsubsection{Discovery}

A total of 1144 patients with an ischemic stroke, and who were treated with reperfusion treatment, met the inclusion criteria and passed the QC; a total of 1139, with 140 cases and 999 controls, had information for the covariates of the analysis. A total of $10,058,599$ SNP passed QC and were evaluated.

There was a total of 141 cases with PH (12\%) and 1003 controls $(88 \%)$. Of these controls, 840 had no hemorrhagic transformation (84\%) and 163 had HI (16\%). Cases were $77 \pm 12$ years old (median \pm interquartile range -IQR-), $52 \%$ were males, $13 \%(11 / 88)$ received intra-arterial fibrinolysis, and none received mechanical thrombectomy. Controls were $75 \pm 16$ years old (median $\pm \mathrm{IQR}), 55 \%$ were males, $5 \%(28 / 620)$ received intra-arterial fibrinolysis, and $6 \%(17 / 286)$ mechanical thrombectomy. In the univariable analysis, the variables significantly associated with PH were a higher NIHSS, higher mean $\mathrm{mRS}$ (0.83 vs. 0.46 in controls), higher percentage of intra-arterial fibrinolysis, and lower percentage of strokes of atherothrombotic etiology. The detailed descriptive analysis can be found in Table 3.

The final sample for the analysis with information for all the covariates included in the association test was 1139 patients, with 140 cases and 999 controls.

In the multivariate analysis with age and the first two PCs, only NIHSS remains significant ( $p$-value $5.36 \times 10^{-3}$ ). Variables with a miss rate $>10 \%$ or those that were not collected in the replication cohort were excluded from this analysis.

\subsubsection{Replication}

A total of 895 patients with an ischemic stroke undergoing reperfusion treatment, met the inclusion criteria and passed the QC. A total of 7,224,265 SNP after QCs were evaluated.

There was a total of 76 cases with $\mathrm{PH}(8 \%)$ and 819 controls (92\%). Cases were $76 \pm 11$ years old (median $\pm \mathrm{IQR}$ ) and $53 \%$ were males. Controls were $72 \pm 17$ years old (median $\pm \mathrm{IQR}$ ) and $52 \%$ were males. In the univariable analysis, the variables significantly associated with $\mathrm{PH}$ were a higher age, a higher proportion of AF and CES, and a higher NIHSS. The detailed descriptive analysis can be found in Table 4 .

The final sample for the analysis with covariates was 895 patients, 76 cases and 819 controls.

\subsection{GWAS}

We did not observe any SNV that reached the GWAS significance threshold $\left(p\right.$-value $\left.<5 \times 10^{-8}\right)$ in the discovery analysis.

The Manhattan and quantile-quantile (QQ) plots, obtained from the discovery and replication cohorts association study, can be visualized in the supplementary Figures S1 and S2, respectively. We did not observe an overall inflation of $p$-values; genomic inflation factor $\lambda$ was 1.007 in the discovery cohort and 0.999 in the replication. 
Table 3. Descriptive analysis of discovery cohort.

\begin{tabular}{|c|c|c|c|c|}
\hline $\begin{array}{c}\text { Variables } \\
\text { (Number of Observations) }\end{array}$ & $\begin{array}{l}\text { Controls } \\
(n=1003)\end{array}$ & $\begin{array}{c}\text { Cases } \\
(n=141)\end{array}$ & $p$-Value & OR (95\% IC) \\
\hline Age $(n=1142)$ & $75 \pm 16$ & $77 \pm 12$ & $6.70 \times 10^{-2}$ & \\
\hline Sex $(n=1144)$, male & $55 \%(548 / 1003)$ & $52 \%(73 / 141)$ & $5.29 \times 10^{-1}$ & $0.89(0.62-1.29)$ \\
\hline HTN $(n=1138)$ & $64 \%(634 / 998)$ & $65 \%(91 / 140)$ & $7.79 \times 10^{-1}$ & $1.07(0.73-1.58)$ \\
\hline $\mathrm{DM}(n=1143)$ & $22 \%(225 / 1002)$ & $30 \%(42 / 141)$ & $5.64 \times 10^{-2}$ & $1.46(0.97-2.19)$ \\
\hline $\operatorname{DLP}(n=821)$ & $38 \%(279 / 728)$ & $37 \%(34 / 93)$ & $8.21 \times 10^{-1}$ & $0.93(0.57-1.48)$ \\
\hline $\mathrm{AF}(n=1140)$ & $37 \%$ (299/999) & $38 \%(53 / 141)$ & $7.93 \times 10^{-2}$ & $1.41(0.96-2.07)$ \\
\hline $\mathrm{SH}(n=788)$ & $21 \%(148 / 698)$ & $18 \%(16 / 90)$ & $3.93 \times 10^{-1}$ & $0.8(0.42-1.44)$ \\
\hline NIHSS $(n=1141)$ & $14 \pm 11$ & $17 \pm 9$ & $4.11 \times 10^{-4}$ & \\
\hline mRS $(n=587)$ & $0 \pm 1$ & $\mathbf{0} \pm \mathbf{1}$ & $1.84 \times 10^{-2}$ & \\
\hline Gly $(n=1104)$ & $119 \pm 44$ & $127 \pm 49$ & $1.02 \times 10^{-1}$ & \\
\hline $\operatorname{SBP}(n=705)$ & $153 \pm 35$ & $158 \pm 37$ & $2.50 \times 10^{-1}$ & \\
\hline $\mathrm{DBP}(n=731)$ & $80 \pm 20$ & $80 \pm 20$ & $4.47 \times 10^{-1}$ & \\
\hline IA $(n=708)$ & $5 \%(28 / 620)$ & $13 \%(11 / 88)$ & $5.12 \times 10^{-3}$ & $3.01(1.30-6.55)$ \\
\hline $\mathrm{TM}(n=336)$ & $6 \%(17 / 286)$ & $0 \%(0 / 50)$ & $8.72 \times 10^{-2}$ & $0(0-1.36)$ \\
\hline CES $(n=1115)$ & $46 \%(451 / 977)$ & $55 \%(76 / 138)$ & $5.57 \times 10^{-2}$ & $1.43(0.98-2.08)$ \\
\hline LAS $(n=1115)$ & $20 \%(193 / 977)$ & $9 \%(11 / 138)$ & $3.91 \times 10^{-4}$ & $0.35(0.17-0.67)$ \\
\hline SVO $(n=1115)$ & $1 \%(12 / 977)$ & $1 \%(2 / 138)$ & $6.88 \times 10^{-1}$ & $1.18(0.13-5.40)$ \\
\hline
\end{tabular}

OR (95\% IC): odds ratio (95\% confidence interval -CI-). HTN: hypertension, DLP: dyslipidemia, AF: atrial fibrillation, SH: smoking habits, NIHSS: National Institutes of Health Stroke Scale, mRS: modified Rankin Score, Gly: initial glycaemia, SBP: systolic blood pressure, DBP: diastolic blood pressure; IA: intra-arterial fibrinolysis, TM: mechanical thrombectomy, CES: cardioembolic stroke, LAS: large artery atherosclerosis stroke, SVO: small vessel occlusion stroke. For quantitative variables, information is expressed as median \pm interquartile range. For categorical variables in frequency $(\%)$. Variables significantly associated with PH $(p$-value $<0.05)$ are highlighted in bold.

Table 4. Descriptive analysis of the replication cohort.

\begin{tabular}{|c|c|c|c|c|}
\hline $\begin{array}{c}\text { Variables } \\
\text { (Number of Observations) }\end{array}$ & $\begin{array}{l}\text { Controls } \\
(n=819)\end{array}$ & $\begin{array}{l}\text { Cases } \\
(n=76)\end{array}$ & $p$-Value & OR (95\% IC) \\
\hline Age $(n=895)$ & $72 \pm 17$ & $76 \pm 11$ & $9.82 \times 10^{-3}$ & \\
\hline Sex $(n=895)$, male & $52 \%(425 / 819)$ & $53 \%(40 / 76)$ & 1 & $1.03(0.63-1.7)$ \\
\hline $\mathrm{DM}(n=643)$ & $18 \%(103 / 586)$ & $16 \%(9 / 57)$ & $8.56 \times 10^{-1}$ & $0.88(0.37-1.89)$ \\
\hline $\mathrm{AF}(n=770)$ & $32 \%(223 / 700)$ & $49 \%(34 / 70)$ & $7.40 \times 10^{-3}$ & $2.02(1.19-3.42)$ \\
\hline NIHSS $(n=895)$ & $11 \pm 11$ & $16 \pm 8$ & $6.33 \times 10^{-6}$ & \\
\hline Gly $(n=464)$ & $120 \pm 42$ & $135 \pm 52$ & $1.35 \times 10^{-1}$ & \\
\hline $\operatorname{CES}(n=670)$ & $60 \%(365 / 604)$ & $77 \%(51 / 66)$ & $7.36 \times 10^{-3}$ & $2.22(1.20-4.36)$ \\
\hline
\end{tabular}

OR (95\% IC): odds ratio (95\% confidence interval). AF: atrial fibrillation, NIHSS: National Institutes of Health Stroke Scale, Gly: initial glycaemia, CES: cardioembolic stroke. For quantitative variables, information is expressed as median \pm interquartile range. For categorical variables, in frequency $(\%)$.

\subsection{Meta-Analysis}

With the meta-analysis, we found a genomic locus with a significant genome-wide association ( $p$-value $<5 \times 10^{-8}$ ). This genomic locus is constituted by $57 \mathrm{SNV}$ in our metaanalysis (Supplementary Table S1). Its leading SNV is 12:59127963:A:G (rs79770152) and it is an intronic variant located in the RP11-362K2.2:RP11-767I20.1 gene, with a $p$-value of $3.90 \times 10^{-8}$ (MAF: 0.09; Beta coefficient: 0.09, standard error (SE): 0.015). 
In addition, a total of 28 genomic loci with nominal SNV were found $\left(p\right.$-value $\left.<1.00 \times 10^{-5}\right)$ (Supplementary Table S2). One of these loci contains a leading SNV that almost reaches statistical significance at genome-wide level, 9:78563802:G:T (rs13297983). It is an intronic variant located in the gene PCSK5 with a $p$-value of $6.10 \times 10^{-8}$ (MAF: 0.07; Beta coefficient: 0.097, SE: 0.017).

None of these two SNVs are eQTL or present chormatin interactions regarding the databases available in FUMA. Table 5 shows the description of the top ten genomic loci with the most significant SNV and Figure 2 the Manhattan plot.

One of the SNV belonging to one of this top ten genomic loci (17:72393744:A:G, rs4348170, $p$-value $1.60 \times 10^{-6}$ ) has been associated in another GWAS with interleukin levels [28]. If we perform a GWAS Catalog search for the genes closest to the leading SNVs of these genomic loci, we find that variants of PCSK5 have been associated with diffuse plaques of aggregated amyloid- $\beta$ peptide in the brain, measurement of tau protein in the form of paired helical filaments, apolipoproteina B, or LDL levels regarding the consumption of alcohol. KLF5 with neutrophil and monocyte count or lymphocyte percentage of leukocytes. TGFBR3 with multiple sclerosis and pulse pressure measurement. C15orf48 with urinary albumin to creatinine ratio, glomerular filtration rate, and albuminuria. RNA5SP448 with LDL and interleukin 12 measurement. SEMA3A with white matter microstructure measurement, cortical thickness, major depression, and alcohol dependence or DNA methylation. EIF3H with neurofibrillary tangles.

Gene-based analysis performed with FUMA took into account a total of 18317 protein coding genes. Therefore, the significant $p$-value corrected for multiple comparisons was $2.73 \times 10^{-6}$. None of the genes reached statistical significance. The most significant associations were SLC30A4 $\left(p\right.$-value $\left.1.82 \times 10^{-5}\right)$ and C15orf48 $\left(p\right.$-value $\left.4.58 \times 10^{-5}\right)$, both in chromosome 15 (Figure 3).

\subsection{MAGMA Analysis and GO Terms}

FUMA platform performs MAGMA gene-set analysis for curated gene sets and gene ontology (GO) terms obtained from MsigDB. The only significant association after adjusting for the Bonferroni method was the GO term (molecular function) myosin $\mathrm{V}$ binding (adjusted $p$-value $2.04 \times 10^{-3}$ ), which definition is the interaction selectively and noncovalently with a class V myosin. Supplementary Table S3 shows the top ten of the most significant curated gene sets and GO terms.

The most relevant GO terms could be visualized on Table 5 .

\subsection{Genetic Correlations}

Genetic correlation analysis detected a shared genetic background among $\mathrm{PH}$ presence and Alzheimer' Disease and white matter hyperintensities (WMH) with a raw $p$-value $<0.05$ (Table 6). None of the traits reached a significant $p$-value adjusted for multiple comparisons ( $p$-value adjusted with Bonferroni method: $4.16 \times 10^{-3}$ ). 
Table 5. The ten genomic loci with its leading SNV.

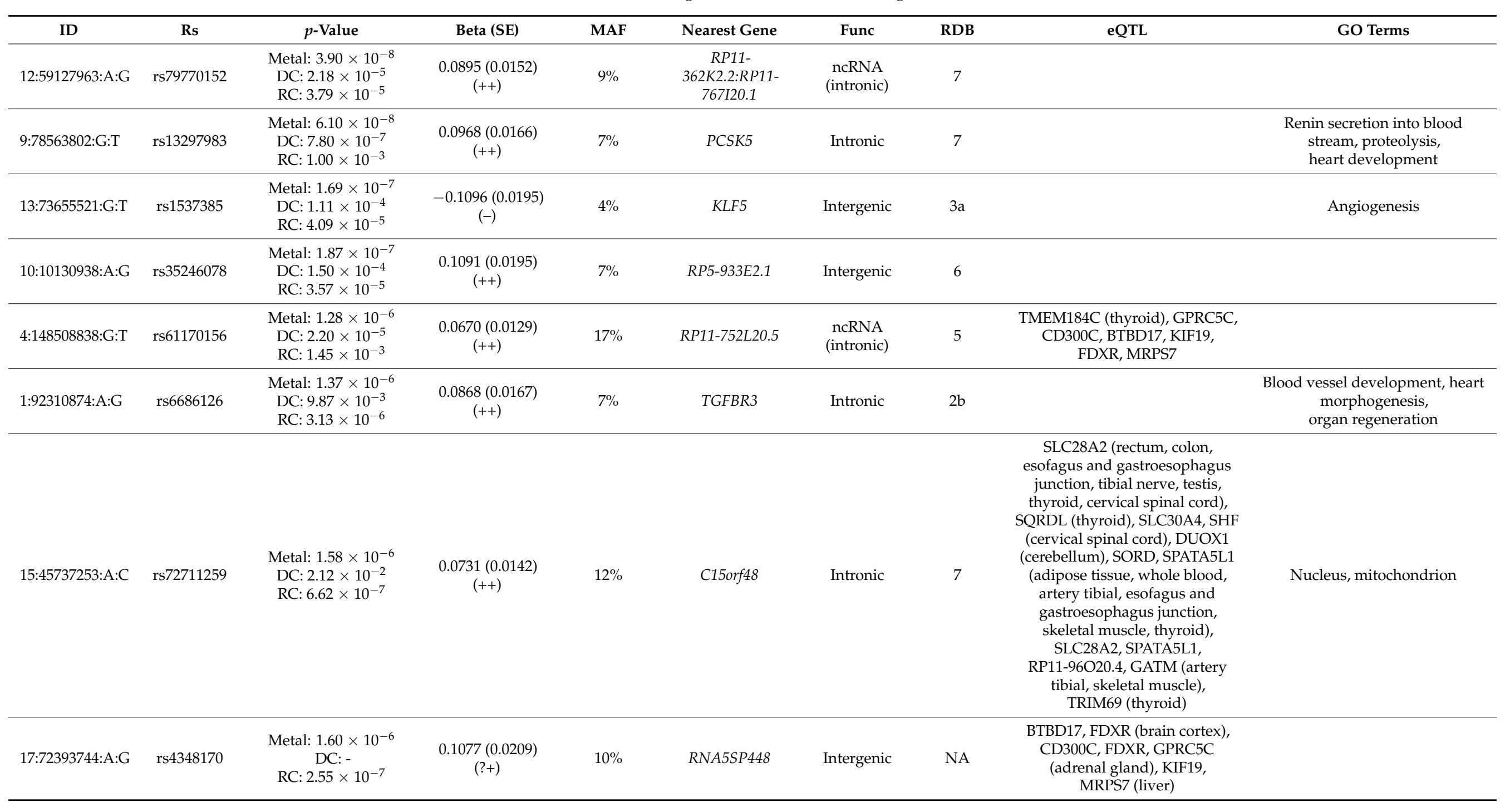


Table 5. Cont.

\begin{tabular}{|c|c|c|c|c|c|c|c|c|c|}
\hline ID & Rs & $p$-Value & Beta (SE) & MAF & Nearest Gene & Func & RDB & eQTL & GO Terms \\
\hline 7:83857204:C:T & rs7802925 & $\begin{array}{c}\text { Metal: } 2.09 \times 10^{-6} \\
\text { DC: } 4.73 \times 10^{-6} \\
\text { RC: } 6.89 \times 10^{-3}\end{array}$ & $\begin{array}{c}-0.0907(0.0178) \\
(-)\end{array}$ & $6 \%$ & SEMA3A & Intronic & 5 & & $\begin{array}{l}\text { Apoptotic process, neuron } \\
\text { migration, nerve development }\end{array}$ \\
\hline
\end{tabular}

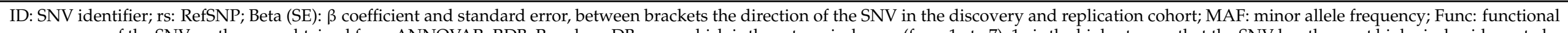

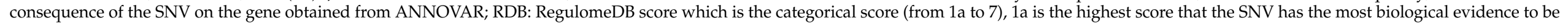

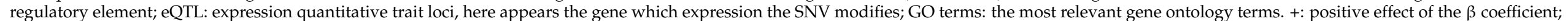
-: negative effect of the $\beta$ coefficient; ?: the SNV was not evaluated; the first symbol corresponds to discovery and the second to replication cohorts.
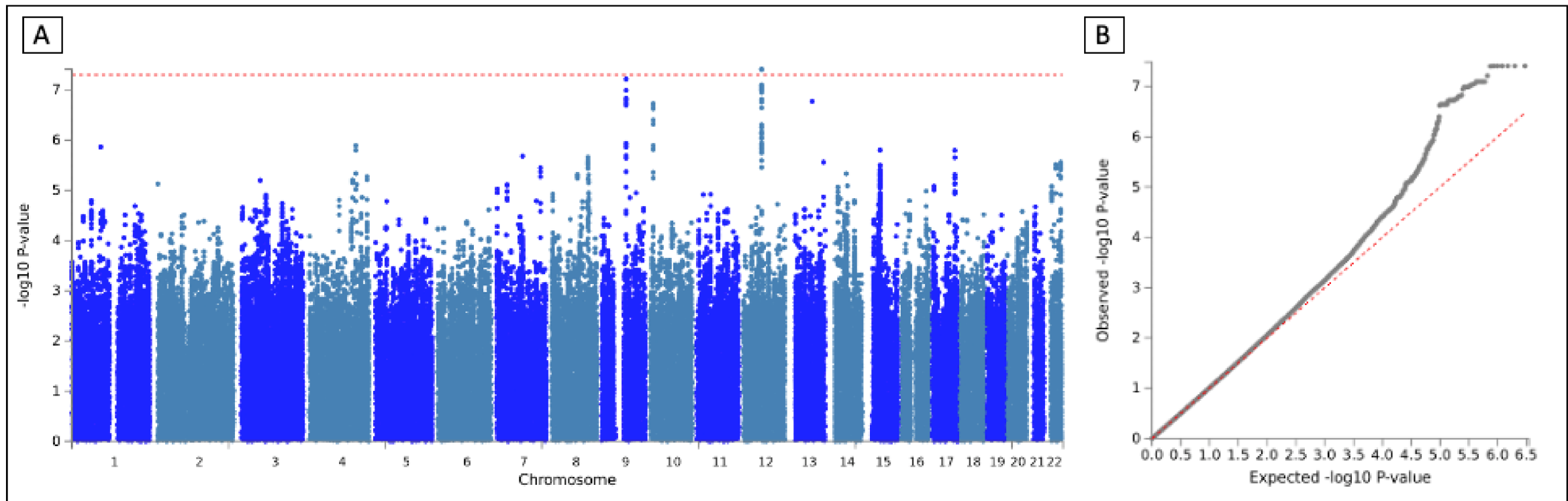

Figure 2. Manhattan and QQ plot of the meta-analysis. (A) Manhattan plot. SNVs were represented by dots and plotted based on their genome-wide association study $p$-values. Red line shows genome-wide significance $\left(p\right.$-value $<5 \times 10^{-8}$ ). (B) QQ plot of the $p$-values obtained after the association testing. The $x$-axis represents the expected $-\log _{10}-p$-value under the null hypothesis and lambda is the median of the resulting chi-squared test statistics divided by the expected median of the chi-squared distribution under the null hypothesis. 


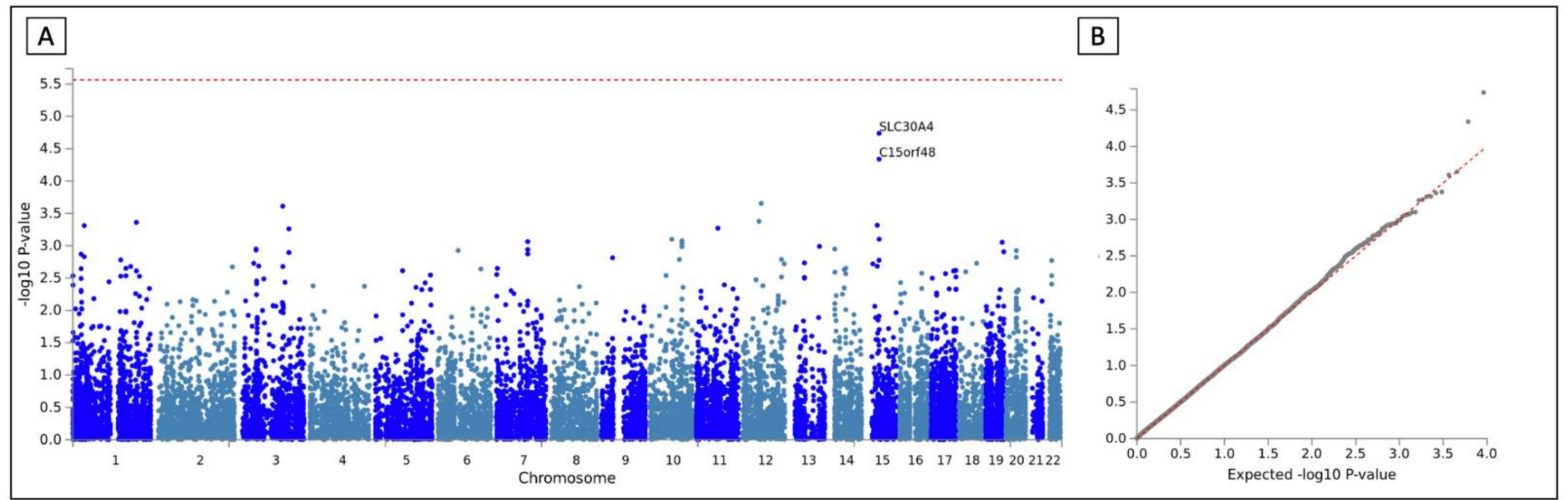

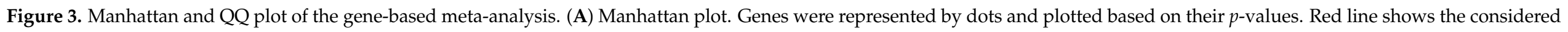

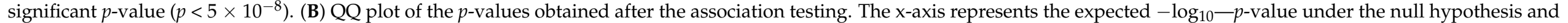
lambda is the median of the resulting chi-squared test statistics divided by the expected median of the chi-squared distribution under the null hypothesis. 
Table 6. Results of the genetic correlation (GNOVA).

\begin{tabular}{|c|c|c|c|c|}
\hline Trait & Rho & Rho SE & Corr & $p$-Value \\
\hline Alzheimer's Disease & 0.049 & 0.021 & 0.200 & $2.15 \times 10^{-2}$ \\
\hline White Matter Hyperintensities & -0.100 & 0.047 & -2.257 & $3.46 \times 10^{-2}$ \\
\hline Deep ICH & 0.089 & 0.80 & 0.141 & $2.66 \times 10^{-1}$ \\
\hline ICH & 0.070 & 0.082 & 0.199 & $3.03 \times 10^{-1}$ \\
\hline SVO & -0.006 & 0.008 & -0.067 & $4.90 \times 10^{-1}$ \\
\hline SBP & -0.007 & 0.013 & -0.021 & $6.06 \times 10^{-1}$ \\
\hline Lobar ICH & 0.031 & 0.080 & 0.189 & $6.96 \times 10^{-1}$ \\
\hline CES & -0.002 & 0.008 & -0.021 & $7.96 \times 10^{-1}$ \\
\hline AIS & -0.002 & 0.008 & -0.017 & $8.32 \times 10^{-1}$ \\
\hline DBP & -0.003 & 0.013 & -0.009 & $8.41 \times 10^{-1}$ \\
\hline LAS & -0.001 & 0.009 & -0.006 & $9.46 \times 10^{-1}$ \\
\hline AS & -0.0005 & 0.008 & -0.005 & $2.66 \times 10^{-1}$ \\
\hline
\end{tabular}

Rho: the genetic covariance estimate; rho SE: standard error of the estimate of rho; Corr: the genetic correlation estimate. ICH: intracerebral hemorrhage; SVO: small vessel occlusion stroke; SBP: systolic blood pressure; CES: cardioembolic stroke; AIS: any ischemic stroke; DBP: diastolic blood pressure; LAS: large artery atherosclerosis stroke; AS: all strokes. Traits with $p$-values $<0.05$ are highlighted in bold.

\section{Discussion}

This is an observational case-control study in order to find genetic risk factors and biological mechanisms associated with brain parenchymal hemorrhagic transformation after reperfusion treatment in ischemic stroke.

In a previous work by our group, we explored which SNVs were associated with hemorrhagic transformation through a GWAS, analyzing extreme phenotypes: PH vs. non hemorrhagic transformation in patients undergoing only IVT [10]. This led to the finding that rs7648433, located in ZBTB46 gene, was associated with this phenotype and it has been implicated in mechanisms such as shear stress and atherosclerosis in other studies.

In the current study, we analyzed patients undergoing IVT and including, additionally, patients with intra-arterial fibrinolysis or mechanical thrombectomy. We wanted to obtain more generalized results, as these therapies are widely used and their window time administration has recently been increased [5-7]. This longer time-window administration may lead to an increase of hemorrhagic complications, one of the major problems of these treperfusion therapies. Understanding why a patient may develop PH including patients underwent any type of reperfusion treatment may be of great interest, as this subtype is the one with the highest rates of morbi-mortality [2,4].

In addition, we have added other HT subtypes different from $\mathrm{PH}$ to the group of controls (HI). This strategy is interesting to find genetic risk factors associated exclusively to $\mathrm{PH}$ in contrast to our previous work [10], as we are avoiding any possible genetic risk factor that could be associated to both, $\mathrm{HI}$ and $\mathrm{PH}$.

Including HI patients and all reperfusion therapies, we could increase the number of cases respect to previous studies, increasing our statistical power and analyzing the major genetic study performed in this field. In our previous work, we analyzed 1904 patients and in our present study, we were able to analyze 2034 patients.

The differences in these sample sizes are due to the slight increase in the number of cohorts introduced, the generalization of the study to patients who had undergone intraarterial fibrinolysis or mechanical thrombectomy as a second intention, and the different QC carried out.

Although we did not find statistically significant SNVs after adjusting for multiple comparisons in our discovery cohort, the meta-analysis did allow us to detect rs79770152 
with a $p$-value $3.90 \times 10^{-8}$, an intronic variant located in the RP11-362K2.2:RP11-767I20.1 genes, which are uncharacterized genes. We found that the lncRNAs are supposed to likely exert their functions in other genomic locations (trans-regulation) [29].

Another SNV very close to be genome-wide significant was rs13297983 with a $p$-value $6.10 \times 10^{-8}$, an intronic variant located in the gene PCSK5.

From these leading SNVs of the first ten loci, we can point out that there is one with the most biological evidence to be a regulatory element: rs6686126, an intronic variant located in TGFBR3. In addition, some of these SNVs are eQTL which regulate the expression of different genes in tissues such as the brain, arteries, and peripheral nerves. None of these two SNVs most significant are eQTL or present chromatin interactions regarding the databases available in FUMA.

All the leading SNVs that constituted the top ten most significant variants, followed the same direction of effect in the discovery and replication cohorts. Except rs4348170, which was not present in the discovery cohort. Furthermore, some of the GO terms were related with angiogenesis or neuronal development. This is noteworthy, since the blood vessel is of relevance in the $\mathrm{PH}$ and neuronal apoptosis in the prognosis.

Interestingly, several of the genes from the genes included in these loci have been associated in other GWAS studies to aggregated amyloid- $\beta$ peptide and tau protein such as PCSK5 or EIF3H [30]. SEMA3A has been associated with cortical thickness and white matter microstructure measurement [31], parameters related to cognitive impairment. SEMA3A gene was also found in the GWAS performed previously by our group ( $p$ value: $7.85 \times 10^{-8}$ ) [10].

We have also found that Alzheimer's disease, the leading cause of dementia characterized by amyloid- $\beta$ and tau aggregates, shares a genetic background with a predisposition to $\mathrm{PH}$ in patients undergoing reperfusion treatment (raw $p$-value $<0.05$ ). Moreover, we found that $\mathrm{WMH}$ also share a genetic background with $\mathrm{PH}$. In previous results from our group, we also observed this genetic correlation with WMH and also with ICH that has not been observed in the current work [10]. We could hypothesize that the lack of this association could be due to the fact that it shares genetic background with HT but not so much with $\mathrm{PH}$, or simply due to a lack of statistical power.

The effect of IVT on overall HT in patients with dementia is controversial in the literature [32]. Some authors conclude that ITV did not increase the risk of HT in the patients with dementia compared to the controls without dementia, that underwent IVT [32].

Our results suggest that dementia might play a role in the development of $\mathrm{PH}$ due to Alzheimer's disease and WMH share a genetic background with $\mathrm{PH}$, although these associations did not remain significant after adjusting for multiple comparisons. Besides, we found SNVs (from the genes PCSK5, EIF3H, and SEMA3A) related to amyloid- $\beta$, tau protein, cortical thickness, or WMH. Moreover, the occurrence and localization of cerebral microbleeds (CMBs) associated with IVT-related hemorrhagic complications could indicate an underlying cerebral amyloid angiopathy [33]. This pathology is characterized by the presence of amyloid- $\beta$ aggregated in the vascular walls of the brain, leading to dementia and a predisposition to ICH. That could indicate that patients who may develop amyloid angiopathy in the future may have an increased risk of HT. However, we did not find a genetic correlation between ICH or ICH subtypes with PH occurrence in our study.

PCSK5 [34] and RNA5SP448 [35] has been found to be associated with LDL levels, a molecule that has been shown to promote inflammation [36]. Actually, it has been found that lower LDL cholesterol levels had been associated with HT [3]. KLF5 has been associated with neutrophil and monocyte count or lymphocyte percentage of leukocytes [37], and RNA5SP448 with interleukin 12 [38]. Both interleukins and the neutrophil-to-lymphocyte ratio (NLR) have been shown to be a marker associated with inflammation; a high NLR can predict HT [39]. This suggests that inflammation may play an important role in the development of PH. Actually, it has been observed that r-tPA mobilizes immune cells that exacerbate hemorrhagic transformation in stroke [40]. 
TGFBR3 has been associated with pulse pressure measurement. Besides, the SNV found with nominal significance: 1:92310874:A:G, an intronic variant located in TGFBR3, has a RegulomeBD score of $2 \mathrm{~b}$. In addition, blood pressure variability was found to be correlated with HT [41]. Nevertheless, we failed to find a genetic correlation between SBP and DBP with PH.

It is also worth noting that myosin $\mathrm{V}$ binding was the GO term significantly associated with PH. Myosin V is primarily found in the central nervous system serving as neuronal marker [42] and has been linked to recycling endosomes and exocytosis of secretory MMP2 and MMP9 which have been widely associated with $\mathrm{TH}$ [43-45].

Regarding limitations, one of the most important is the small sample size of both the discovery and replication cohorts, even though it is one of the largest made in this topic. This is probably the root cause of not finding significant SNVs in the discovery cohort. For this reason, to increase our statistical power, we performed the meta-analysis that showed a genome-wide significant SNV and another that was almost significant. Another limitation is the lack of replication in an independent cohort. However, the same direction of effect observed for the most significant SNVs in the discovery and replication cohorts indicates that the results are consistent.

Another limitation is the Spanish origin of all the patients from the discovery cohort, this might make it difficult to generalize the results to other populations. To overcome this limitation, the replication cohort included patients from Poland and Finland. Likewise, the lack of values for the variable of the time elapsed between the onset of symptoms and the administration of treatment may limit our results. Furthermore, the fact that we did not have any patient with mechanical thrombectomy who presented PH limits the generalization of our results to this subgroup of patients. Therefore, studies with a larger sample size, incorporating more variables, and more patients subjected to mechanical thrombectomy will be necessary to establish more robust conclusions.

\section{Conclusions}

With this meta-analysis, we have found a new locus significantly associated with the risk of $\mathrm{PH}$ in patients treated with the different types of reperfusion therapies used in the clinical practice. Correlation analysis has shown us shared background genetics between PH and Alzheimer's disease and WMH. Moreover, the analysis of the most significant genomic loci supports this relationship, as the nearest genes associated with the leading SNVs have been related to aggregated amyloid- $\beta$, tau protein, or white matter microstructure. However, also of great interest is that other traits related to these SNVs pointed to the importance that inflammation may play in the risk of developing PH. Further studies are needed to test these hypotheses.

Supplementary Materials: The following are available online at https://www.mdpi.com/article/10 $.3390 /$ jcm10143137/s1, Figure S1: Manhattan and QQ plot of the discovery cohort; Figure S2: Manhattan and QQ plot of the discovery cohort; Table S1: SNVs belonging to the genomic locus with the leading SNP being significant at GWAS level; Table S2: Description of the GWAS significant locus and the 28 nominal significant loci; and Table S3: Top ten of the most significant curated gene sets and gene ontology terms obtained from MsigDB.

Author Contributions: Conception and design of the work and writing-original draft preparation: E.M., J.C.-M. and I.F.-C.; Writing-review and editing: All authors. All authors have read and agreed to the published version of the manuscript. 
Funding: This work was supported by grants from the Instituto de Salud Carlos III (PI 11/0176), Generación Project, Maestro Project (PI18/01338), INVICTUS+ network, Epigenesis Project (Marató de TV3), FEDER funds. E. Muiño is supported by a Río Hortega Contract (CM18/00198) from the Instituto de Salud Carlos III. J. Cárcel-Márquez is supported by an AGAUR Contract (agència de gestió d'ajuts universitaris i de recerca; FI_DGR 2020, grant number 2020FI_B1 00157) co-financed with Fons Social Europeu (FSE). C. Gallego-Fabrega is supported by a Sara Borrell Contract (CD20/00043) from Instituto de Salud Carlos III and Fondo Europeo de Desarrollo Regional (ISCIII-FEDER). M. Lledós is supported by a PFIS Contract (Contratos Predoctorales de Formación en Investigación en Salud) from the Instituto de Salud Carlos III. I (FI19/00309). Fernández-Cadenas (CP12/03298), Tomás Sobrino (CPII17/00027), and Francisco Campos (CPII19/00020) are supported by a research contract from Miguel Servet Program from the Instituto de Salud Carlos III.

Institutional Review Board Statement: The study was conducted according to the guidelines of the Declaration of Helsinki, and approved by the local Ethics Committee of every hospital participant.

Informed Consent Statement: Informed consent was obtained from all subjects involved in the study.

Data Availability Statement: The data presented in this study are available on request from the corresponding author.

Acknowledgments: We are grateful to Lucía Muñoz (Hospital Germans Trias i Pujol), Anna Penalba (Vall d'Hebron Research Institute), Uxue Lascano (IMIM-Hospital del Mar), Carmen Jimenez (Hospital Universitari Son Espases), Elisa Cortijo (Hospital Clínico Universitario), Esther Sarasola Diez (Hospital de Basurto), Carmen Gubern (Josep Trueta University Hospital), Aki Havulinna (Institute for Molecular Medicine Finland), Veikko Salomaa (Institute for Molecular Medicine Finland), and Antoni Ferens (Jagiellonian University) for their contribution to patient recruitment; and to Agustin Ruiz and Oscar Sotolongo (Fundació ACE) for their technical support.

Conflicts of Interest: The authors declare no conflict of interest.

\section{References}

1. Feigin, V.L.; Norrving, B.; Mensah, G.A. Global Burden of Stroke. Circ. Res. 2017, 120, 439-448. [CrossRef]

2. Fiorelli, M.; Bastianello, S.; von Kummer, R.; del Zoppo, G.J.; Larrue, V.; Lesaffre, E.; Ringleb, A.P.; Lorenzano, S.; Manelfe, C.; Bozzao, L. Hemorrhagic Transformation within 36 Hours of a Cerebral Infarct. Stroke 1999, 30, 2280-2284. [CrossRef]

3. Pande, S.D.; Win, M.M.; Khine, A.A.; Zaw, E.M.; Manoharraj, N.; Lolong, L.; Tin, A.S. Haemorrhagic Transformation Following Ischaemic Stroke: A Retrospective Study. Sci. Rep. 2020, 10, 5319. [CrossRef] [PubMed]

4. D'Amelio, M.; Terruso, V.; Famoso, G.; Di Benedetto, N.; Realmuto, S.; Valentino, F.; Ragonese, P.; Savettieri, G.; Aridon, P. Early and Late Mortality of Spontaneous Hemorrhagic Transformation of Ischemic Stroke. J. Stroke Cerebrovasc. Dis. 2014, 23, 649-654. [CrossRef]

5. Thomalla, G.; Simonsen, C.Z.; Boutitie, F.; Andersen, G.; Berthezene, Y.; Cheng, B.; Cheripelli, B.; Cho, T.-H.; Fazekas, F.; Fiehler, J.; et al. MRI-Guided Thrombolysis for Stroke with Unknown Time of Onset. N. Engl. J. Med. 2018, 379, 611-622. [CrossRef] [PubMed]

6. Nogueira, R.G.; Jadhav, A.P.; Haussen, D.C.; Bonafe, A.; Budzik, R.F.; Bhuva, P.; Yavagal, D.R.; Ribo, M.; Cognard, C.; Hanel, R.A.; et al. Thrombectomy 6 to $24 \mathrm{~h}$ after Stroke with a Mismatch between Deficit and Infarct. N. Engl. J. Med. 2018, 378, 11-21. [CrossRef]

7. Albers, G.W.; Marks, M.P.; Kemp, S.; Christensen, S.; Tsai, J.P.; Ortega-Gutierrez, S.; McTaggart, R.A.; Torbey, M.T.; Kim-Tenser, M.; Leslie-Mazwi, T.; et al. Thrombectomy for Stroke at 6 to $16 \mathrm{~h}$ with Selection by Perfusion Imaging. N. Engl. J. Med. 2018, 378, 708-718. [CrossRef] [PubMed]

8. del Río-Espínola, A.; Fernández-Cadenas, I.; Giralt, D.; Quiroga, A.; Gutiérrez-Agulló, M.; Quintana, M.; Fernández-Álvarez, P.; Domingues-Montanari, S.; Mendióroz, M.; Delgado, P.; et al. A Predictive Clinical-Genetic Model of Tissue Plasminogen Activator Response in Acute Ischemic Stroke. Ann. Neurol. 2012, 72, 716-729. [CrossRef]

9. Carrera, C.; Cullell, N.; Torres-Águila, N.; Muiño, E.; Bustamante, A.; Dávalos, A.; López-Cancio, E.; Ribó, M.; Molina, C.A.; Giralt-Steinhauer, E.; et al. Validation of a Clinical-Genetics Score to Predict Hemorrhagic Transformations after RtPA. Neurology 2019, 93, e851-e863. [CrossRef]

10. Carrera, C.; Cárcel-Márquez, J.; Cullell, N.; Torres-Águila, N.; Muiño, E.; Castillo, J.; Sobrino, T.; Campos, F.; Rodríguez-Castro, E.; Llucia-Carol, L.; et al. Single Nucleotide Variations in ZBTB46 Are Associated with Post-Thrombolytic Parenchymal Haematoma. Brain 2021. [CrossRef]

11. Kunkle, B.W.; Grenier-Boley, B.; Sims, R.; Bis, J.C.; Damotte, V.; Naj, A.C.; Boland, A.; Vronskaya, M.; van der Lee, S.J.; Amlie-Wolf, A.; et al. Genetic Meta-Analysis of Diagnosed Alzheimer's Disease Identifies New Risk Loci and Implicates A $\beta$, Tau, Immunity and Lipid Processing. Nat. Genet. 2019, 51, 414-430. [CrossRef] 
12. Chung, J.; Marini, S.; Pera, J.; Norrving, B.; Jimenez-Conde, J.; Roquer, J.; Fernandez-Cadenas, I.; Tirschwell, D.L.; Selim, M.; Brown, D.L.; et al. Genome-Wide Association Study of Cerebral Small Vessel Disease Reveals Established and Novel Loci. Brain 2019, 142, 3176-3189. [CrossRef] [PubMed]

13. Mola-Caminal, M.; Carrera, C.; Soriano-Tárraga, C.; Giralt-Steinhauer, E.; Díaz-Navarro, R.M.; Tur, S.; Jiménez, C.; Medina-Dols, A.; Cullell, N.; Torres-Aguila, N.P.; et al. PATJ Low Frequency Variants Are Associated with Worse Ischemic Stroke Functional Outcome: A Genome-Wide Meta-Analysis. Circ. Res. 2019, 124, 114-120. [CrossRef]

14. Fernández-Cadenas, I.; Mendióroz, M.; Giralt, D.; Nafria, C.; Garcia, E.; Carrera, C.; Gallego-Fabrega, C.; Domingues-Montanari, S.; Delgado, P.; Ribó, M.; et al. GRECOS Project (Genotyping Recurrence Risk of Stroke). Stroke 2017, 48, 1147-1153. [CrossRef]

15. Heitsch, L.; Ibanez, L.; Carrera, C.; Pera, J.; Jimenez-Conde, J.; Slowik, A.; Strbian, D.; Fernandez-Cadenas, I.; Montaner, J.; Lee, J.-M. Meta-Analysis of Transethnic Association (MANTRA) Reveals Loci Associated with Neurological Instability after Acute Ischemic Stroke. In Proceedings of the International Stroke Conference, Houston, TX, USA, 21-24 February 2017.

16. Roquer, J.; Rodríguez-Campello, A.; Gomis, M.; Jiménez-conde, J.; Cuadrado-godia, E.; Vivanco, R.; Giralt, E.; Sepúlveda, M.; Pont-Sunyer, C.; Cucurella, G.; et al. Acute Stroke Unit Care and Early Neurological Deterioration in Ischemic Stroke. J. Neurol. 2008, 255, 1012-1017. [CrossRef] [PubMed]

17. Robberecht, W.; Vanhees, L.; Lemmens, R.; Pandolfo, M.; Thijs, V.; Goris, A. Variant on 9p21 Strongly Associates with Coronary Heart Disease, but Lacks Association with Common Stroke. Eur. J. Hum. Genet. 2009, 4, 1287-1293. [CrossRef]

18. Charidimou, A.; Pasi, M. Microbleeds Evolution and Remote Hemorrhage Post-TPA: Red Meets White Revisited. Neurology 2019, 92, 307-308. [CrossRef] [PubMed]

19. Jiang, L.; Zheng, Z.; Qi, T.; Kemper, K.E.; Wray, N.R.; Visscher, P.M.; Yang, J. A Resource-Efficient Tool for Mixed Model Association Analysis of Large-Scale Data. Nat. Genet. 2019, 51, 1749-1755. [CrossRef]

20. Willer, C.J.; Li, Y.; Abecasis, G.R. METAL: Fast and Efficient Meta-Analysis of Genomewide Association Scans. Bioinformatics 2010, 26, 2190-2191. [CrossRef] [PubMed]

21. Watanabe, K.; Taskesen, E.; Van Bochoven, A.; Posthuma, D. Functional Mapping and Annotation of Genetic Associations with FUMA. Nat. Commun. 2017, 8, 1826. [CrossRef]

22. Malik, R.; Chauhan, G.; Traylor, M.; Sargurupremraj, M.; Okada, Y.; Mishra, A.; Rutten-Jacobs, L.; Giese, A.K.A.-K.; van der Laan, S.W.S.W.; Gretarsdottir, S.; et al. Multiancestry Genome-Wide Association Study of 520,000 Subjects Identifies 32 Loci Associated with Stroke and Stroke Subtypes. Nat. Genet. 2018, 50, 524-537. [CrossRef]

23. Woo, D.; Falcone, G.J.; Devan, W.J.; Brown, W.M.; Biffi, A.; Howard, T.D.; Anderson, C.D.; Brouwers, H.B.; Valant, V.; Battey, T.W.K.; et al. Meta-Analysis of Genome-Wide Association Studies Identifies 1q22 as a Susceptibility Locus for Intracerebral Hemorrhage. Am. J. Hum. Genet. 2014, 94, 511-521. [CrossRef]

24. Traylor, M.; Tozer, D.J.; Croall, I.D.; Lisiecka Ford, D.M.; Olorunda, A.O.; Boncoraglio, G.; Dichgans, M.; Lemmens, R.; Rosand, J.; Rost, N.S.; et al. Genetic Variation in PLEKHG1 Is Associated with White Matter Hyperintensities ( $\mathrm{n}=11,226)$. Neurology 2019, 92, E749-E757. [CrossRef]

25. Willer, C.J.; Schmidt, E.M.; Sengupta, S.; Peloso, G.M.; Gustafsson, S.; Kanoni, S.; Ganna, A.; Chen, J.; Buchkovich, M.L.; Mora, S.; et al. Discovery and Refinement of Loci Associated with Lipid Levels. Nat. Genet. 2018, 176, 139-148. [CrossRef]

26. Evangelou, E.; Warren, H.R.; Mosen-Ansorena, D.; Mifsud, B.; Pazoki, R.; Gao, H.; Ntritsos, G.; Dimou, N.; Cabrera, C.P.; Karaman, I.; et al. Genetic Analysis of over One Million People Identifies 535 New Loci Associated with Blood Pressure Traits. Nat. Genet. 2018, 50, 1412-1425. [CrossRef]

27. Morris, A.P.; Voight, B.F.; Teslovich, T.M.; Ferreira, T.; Segre, A.V.; Steinthorsdottir, V.; Strawbridge, R.J.; Khan, H.; Grallert, H.; Mahajan, A.; et al. Large-Scale Association Analysis Provides Insights into the Genetic Architecture and Pathophysiology of Type 2 Diabetes. Nat. Genet. 2012, 44, 981-990. [CrossRef] [PubMed]

28. Bennett, D.A. How Can I Deal with Missing Data in My Study? Aust. N. Z. J. Public Health 2001, 25, 464-469. [CrossRef]

29. Müller, R.; Weirick, T.; John, D.; Militello, G.; Chen, W.; Dimmeler, S.; Uchida, S. ANGIOGENES: Knowledge Database for Protein-Coding and Noncoding RNA Genes in Endothelial Cells. Sci. Rep. 2016, 6, 1-8. [CrossRef] [PubMed]

30. Wang, H.; Yang, J.; Schneider, J.A.; De Jager, P.L.; Bennett, D.A.; Zhang, H.Y. Genome-Wide Interaction Analysis of Pathological Hallmarks in Alzheimer's Disease. Neurobiol. Aging 2020, 93, 61-68. [CrossRef] [PubMed]

31. van der Meer, D.; Frei, O.; Kaufmann, T.; Shadrin, A.A.; Devor, A.; Smeland, O.B.; Thompson, W.K.; Fan, C.C.; Holland, D.; Westlye, L.T.; et al. Understanding the Genetic Determinants of the Brain with MOSTest. Nat. Commun. 2020, 11, 1-9. [CrossRef] [PubMed]

32. Alshekhlee, A.; Li, C.C.; Chuang, S.Y.; Vora, N.; Edgell, R.C.; Kitchener, J.M.; Kale, S.P.; Feen, E.; Piriyawat, P.; Callison, R.C.; et al. Does Dementia Increase Risk of Thrombolysis?: A Case-Control Study. Neurology 2011, 76, 1575-1580. [CrossRef] [PubMed]

33. Braemswig, T.B.; Villringer, K.; Turc, G.; Erdur, H.; Fiebach, J.B.; Audebert, H.J.; Endres, M.; Nolte, C.H.; Scheitz, J.F. Predictors of New Remote Cerebral Microbleeds after IV Thrombolysis for Ischemic Stroke. Neurology 2019, 92, E630-E638. [CrossRef] [PubMed]

34. De Vries, P.S.; Brown, M.R.; Bentley, A.R.; Sung, Y.J.; Winkler, T.W.; Ntalla, I.; Schwander, K.; Kraja, A.T.; Guo, X.; Franceschini, N.; et al. Multiancestry Genome-Wide Association Study of Lipid Levels Incorporating Gene-Alcohol Interactions. Am. J. Epidemiol. 2019, 188, 1033-1054. [CrossRef] 
35. Noordam, R.; Bos, M.M.; Wang, H.; Winkler, T.W.; Bentley, A.R.; Kilpeläinen, T.O.; de Vries, P.S.; Sung, Y.J.; Schwander, K.; Cade, B.E.; et al. Multi-Ancestry Sleep-by-SNP Interaction Analysis in 126,926 Individuals Reveals Lipid Loci Stratified by Sleep Duration. Nat. Commun. 2019, 10, 5121. [CrossRef]

36. Puig, N.; Montolio, L.; Camps-Renom, P.; Navarra, L.; Jiménez-Altayó, F.; Jiménez-Xarrié, E.; Sánchez-Quesada, J.L.; Benitez, S. Electronegative LDL Promotes Inflammation and Triglyceride Accumulation in Macrophages. Cells 2020, 9, 583. [CrossRef]

37. Chen, M.H.; Raffield, L.M.; Mousas, A.; Sakaue, S.; Huffman, J.E.; Moscati, A.; Trivedi, B.; Jiang, T.; Akbari, P.; Vuckovic, D.; et al. Trans-Ethnic and Ancestry-Specific Blood-Cell Genetics in 746,667 Individuals from 5 Global Populations. Cell 2020, 182, 1198-1213. [CrossRef]

38. Ahola-Olli, A.V.; Würtz, P.; Havulinna, A.S.; Aalto, K.; Pitkänen, N.; Lehtimäki, T.; Kähönen, M.; Lyytikäinen, L.P.; Raitoharju, E.; Seppälä, I.; et al. Genome-Wide Association Study Identifies 27 Loci Influencing Concentrations of Circulating Cytokines and Growth Factors. Am. J. Hum. Genet. 2017, 100, 40-50. [CrossRef]

39. Zhang, R.; Wu, X.; Hu, W.; Zhao, L.; Zhao, S.; Zhang, J.; Chu, Z.; Xu, Y. Neutrophil-to-Lymphocyte Ratio Predicts Hemorrhagic Transformation in Ischemic Stroke: A Meta-Analysis. Brain Behav. 2019, 9, 1-9. [CrossRef]

40. Shi, K.; Zou, M.; Jia, D.M.; Shi, S.; Yang, X.; Liu, Q.; Dong, J.F.; Sheth, K.N.; Wang, X.; Shi, F.D. TPA Mobilizes Immune Cells That Exacerbate Hemorrhagic Transformation in Stroke. Circ. Res. 2021, 128, 62-75. [CrossRef]

41. Kim, T.J.; Park, H.K.; Kim, J.M.; Lee, J.S.; Park, S.H.; Jeong, H.B.; Park, K.Y.; Rha, J.H.; Yoon, B.W.; Ko, S.B. Blood Pressure Variability and Hemorrhagic Transformation in Patients with Successful Recanalization after Endovascular Recanalization Therapy: A Retrospective Observational Study. Ann. Neurol. 2019, 85, 574-581. [CrossRef] [PubMed]

42. Langford, G.M.; Molyneaux, B.J. Myosin V in the Brain: Mutations Lead to Neurological Defects. Brain Res. Rev. 1998, $28,1-8$. [CrossRef]

43. Montaner, J.; Molina, C.A.; Monasterio, J.; Abilleira, S.; Arenillas, J.F.; Ribó, M.; Quintana, M.; Alvarez-Sabín, J. Matrix Metalloproteinase-9 Pretreatment Level Predicts Intracranial Hemorrhagic Complications after Thrombolysis in Human Stroke. Circulation 2003, 107, 598-603. [CrossRef] [PubMed]

44. Cuadrado, E.; Ortega, L.; Hernández-Guillamon, M.; Penalba, A.; Fernández-Cadenas, I.; Rosell, A.; Montaner, J. Tissue Plasminogen Activator (t-PA) Promotes Neutrophil Degranulation and MMP-9 Release. J. Leukoc. Biol. 2008, 84, 207-214. [CrossRef]

45. Zheng, L.; Xiong, Y.; Liu, J.; Yang, X.; Wang, L.; Zhang, S.; Liu, M.; Wang, D. MMP-9-Related MicroRNAs as Prognostic Markers for Hemorrhagic Transformation in Cardioembolic Stroke Stroke Patients. Front. Neurol. 2019, 10, 1-7. [CrossRef] [PubMed] 